\title{
Care of Children
}

Coming to the United States for Safety

Under the Attorney General's Order

$$
\text { of July 13,1940 }
$$

Standards Prescribed

by the Children's Bureau

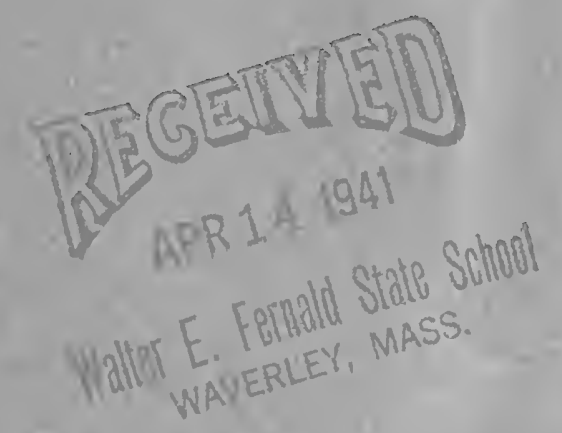

Bureau Publication No. 268

UNITED STATES DEPARTMENT OF LABOR CHILDREN'S BUREAU 


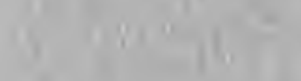

$y=1$

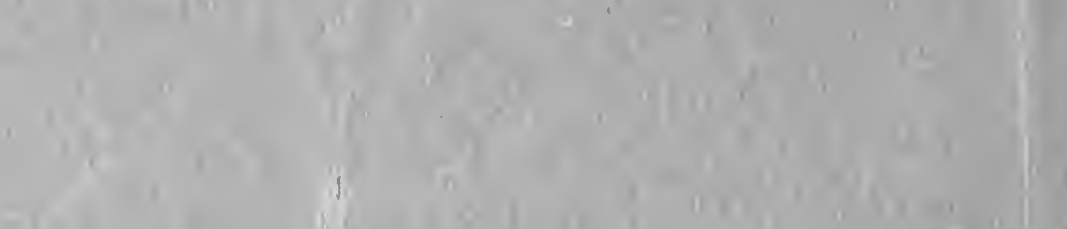

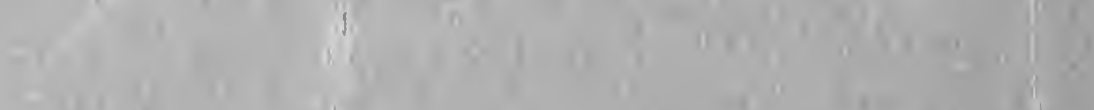

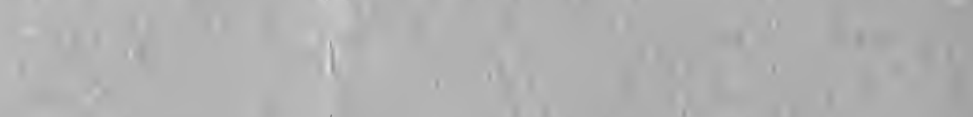
$4 \times$

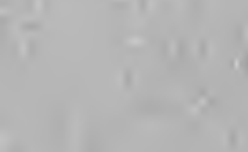




\section{UNITED STATES DEPARTMENT OF LABOR}

Frances Perkins, Secretary

CHILDREN'S BUREAU - Katharine F. Lenroot, Chief

\section{Care of Children}

Coming to the United States for Safety

Under the Attorney General's Order of July 13, 1940

$+$

Standards Prescribed

by the Children's Bureau

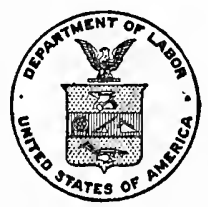

Bureau Publication No. 268

United States

Government Printing Office

Washington : 1941 



\section{Contents}

Foreworl- Page

Care in family homes and in groups $\ldots$

Standards of family-home care for children (for use of foster parents)

Group care of children ............ 5

Standards for child-care agencies................... 7

General policies governing the designation of child-care agencies

Standards of foster care (for use of designated child-care agencies)

Care in reception centers ............. 14

General standards of care of children in reception centers_ $\quad 14$

Medical care of children

Standards for medical care _.

Program for medical care_............... 19

Organization for medical care

Appendix.-Forms used in the designation of agencies.....- 28 
Digitized by the Internet Archive in 2010 with funding from Boston Library Consortium Member Libraries 


\section{Foreword}

Early in June 1940 it became apparent that steps should be taken, through governmental action and private effort, to facilitate the entrance of children from European war zones seeking refuge in the United States, and to assure proper care for these children after arrival. Need for coordinating the efforts of the many agencies and individuals in the United States anxious to provide refuge in this country for such children also became urgent.

The United States Committee for the Care of European Children was organized in June 1940 and was incorporated under the laws of the State of New York on July 3, 1940. As stated in a bulletin of the Committee, the problem of providing a refuge in this country for children from European war zones involves, on the one hand, the overwhelming sentiment of the American people to admit as many such children as possible, and, on the other hand, the duty of the American Government to make certain that every child who enters will be properly cared for and will not become a "public charge." The function of the Committee, as described in the same bulletin, is (1) to clear the way for the admission of children evacuated from war zones in large numbers, and (2) to assure their proper care during their stay. ${ }^{1}$

After conferences between representatives of the Committee and officials of the Department of State, the Department of Justice, and the Department of Labor, the Department of Justice and the Department of State adopted on July 13,1940 , a simplified plan of procedure for the admission of children for refuge from the dangers of war, on either immigration-quota visas ${ }^{2}$ or visitor's visas.

Arrangements may be made either (1) by an individual who wishes to bring a specified child to the United States and who furnishes a United States consul abroad with such affi-

1 So That the Children Can Come, p. 3. Bull. No. 4, United States Committee for the Care of European Children, Inc., New York.

2 Permitting entrance for an indefinite or permanent stay. 
davits and guarantees as may be required under the law to assure his ability to care for the child, or (2) by an organization recognized by the Attorney General as qualified to give corporate affidavits for specified children or for unspecified children to be nominated by representatives of the organization abroad, assuring their proper care in this country in accordance with standards set by the Children's Bureau of the United States Department of Labor. The United States Committee for the Care of European Children, Inc., has submitted to the Attorney General a plan for the care of children which has received his approval, and corporate affidavits submitted by the Committee are accepted by the Attorney General and by United States consular officers as a basis for the issuance of quota or visitor's visas. The corporate affidavit certifies for each child, specified in the affidavit or unspecified, as follows:

1. That the child will not become a public charge.

2. That reception, placement, and care of the child will be in accordance with standards set by the Children's Bureau of the Department of Labor.

3. That the sum of $\$ 50$ required by the Government has been set aside as a safeguard against certain future contingencies, and that it will be placed in a trust fund to be reserved for such purposes upon the arrival of the child in the United States.

As a basis for its corporate assurance on these points the United States Committee has secured, for the most part through its affiliated local information committees, affidavits for individuals guaranteeing support, or support and care in their own homes, and cash contributions. Affidavits assuring home care must state that the child will be cared for in accordance with the standards of the Children's Bureau.

The Child Care Division of the Committee is responsible for the care of the children from the time they arrive at the port of entry. In the case of children coming through Canada it cooperates with Canadian authorities in the reception and care of children in transit. This division has set up centers for reception care of children in New York, and is responsible for the review of homes and the placement and supervision of children through private child-caring agencies designated by 
the Children's Bureau, in consultation with State departments of public welfare.

A total of 184 child-caring agencies in 34 States were designated provisionally by the Children's Bureau, in consultation with State welfare departments, for immediate service in the placement and supervision of European children. By December 1940 the facilities of 221 agencies had been carefully reviewed by both the State agencies and the Children's Bureau and 184 agencies in 40 States had received final designations. ${ }^{3}$

Generous cooperation in the development of the program has been given by State welfare agencies, State health officials, Nation-wide organizations, and especially by local designated agencies and local information committees. Procedures and policies have been developed in cooperation with the children's committee of the State Council of Public Assistance and Welfare Administrators; a committee of the American Academy of Pediatrics, and a special advisory group on medical care called together by the Children's Bureau, which included members of the Children's Bureau Advisory Committee on Pediatrics and representatives of the United States Committee for the Care of European Children; and the Advisory Committee to the Child Care Division of the United States Committee for the Care of European Children.

In addition to maintaining relationships with official State agencies in regard to the program, giving general advisory service with reference to development and application of standards, and designating child-care agencies for service, the Children's Bureau, with the assistance of the Committee, is compiling and maintaining a central register of all children coming to the United States for refuge from the dangers of war, not arriving to join a parent already here nor accompanied by both parents. ${ }^{4}$ Through the register, State health and welfare agencies are notified of children being cared for in their States.

\footnotetext{
${ }^{3}$ See appendix, p. 28, for forms used in the designation of agencies.

${ }^{4}$ The register containcd on January 31,1941 , the names of 5,530 elildren, slightly more than two-thirds of whom were destined to relatives living in this country or were accompanied by relatives.
} 
On October 3, 1940, it was announced that because of the dangers of ocean transportation, the British Government's encouragement of the evacuation of children overseas would be withdrawn for the present. In accordance with this decision the United States Committee for the Care of European Children released the following statement of policy:

In looking ahead to its function over the next few months the United States Committee for the Care of European Children, Ine., has reached several conelusions. First, it is not going out of business. It must continue to take care of the children who have come here as its obligation and this the Committee will do to the fullest extent originally contemplated.

Second, it will continue to give its advice and help in relation to children who have eome over under private auspices.

Third, while the Committee adheres to its conelusion that it will not take the responsibility of assisting ehildren now abroad to run the risks of ocean passage at this time, it regards it as part of its essential function to aid in any way possible children who do arrive here as evacuees from the war strieken countries, and that function, too, will be continued during the eoming months.

Fourth, the Committee expresses the view that changing circumstances may require a revision of its program at any time.

The standards for the care of children adopted by the Children's Bureau have been based on the policies and practices that have been accepted and used by qualified agencies in providing care for children in the United States, particularly the standards for child-caring agencies and for medical care developed by the Child Welfare League of America. ${ }^{5}$ This publication brings together all the standards that have been issued for the use of foster parents, reception centers, and child-caring agencies. In order of issuance these standards are:

General Standards for Child-Caring Agencies Designated for

Service to European Children, June 28, 1940.

Standards of Family-Home Care for Children (for use of foster parents), August 1, 1940.

Standards of Foster Care (for use of designated ehild-care agencies), August 2, 1940.

s Standards of Foster Care for Children in Institutions, 1937, and A Health Program for Children in Foster Care, 1938. Child Welfare League of America, New York. 
General Standards of Care of Children in Reception Centers, August 14, 1940.

Standards for Medical Care of Children, August 28, 1940.

Memorandum Concerning Group Care of Children (issued in tentative form September 20, 1940).

The standards are presented as first issued except for minor editorial or interpretive changes. The order in which they are given in this bulletin is not the same as the chronological order of issuance. 



\section{CARE OF CHILDREN \\ COMING TO THE UNITED STATES \\ FOR SAFETY}

\section{Care in Family Homes and in Groups}

The Children's Bureau and the United States Committee for the Care of European Children have based their policies regarding family-home care and group care of children coming here for safety upon the following premise:

Children coming to the United States for refuge from the dangers of war should be regarded as guests of the people of the Nation. Deprived for the present of care in their own homes by their own people, they should be assured the kind of care which those in the United States concerned with the welfare of children are seeking constantly to make a reality.

It is recognized that children coming to the United States, unlike the children in this country for whom child-caring organizations assume special responsibility, have come for the most part from normal homes representing an average cross section of the family life of the nation whose citizens they are. Some have had group care in the home country: British parents are more inclined than American parents to send their children to boarding schools. The loneliness of a child in a strange land, the necessity for adaptation to different customs in the new home and to a different school program from that with which he is familiar, and the importance of maintaining his sense of belonging to his own people and his own country make it desirable, whenever possible, to keep guest children in touch with one another. On the other hand, the variations in background, temperament, and special needs which characterize children everywhere suggest the superiority, for many children at least, of individual care in an individual home. This plan also offers greater possibility 
than group care for participation in normal family and community relationships and activities. Moreover, many children coming to the United States under the auspices of the Committee, like those coming under consular affidavits, have natural family ties through blood relationship or parental friendship or acquaintance.

In the light of all these considerations, especially the generally recognized values inherent for growing children in home and family life, the Committee in its policies and the Children's Bureau in the standards which it has developed as a basis for Committee action have emphasized home care. When groups of children who have known one another in the home country can be placed in homes in a single community within a radius that will make possible continuing contacts and participation in the same school and community activities, many of the values of home and group care can be combined. On the other hand, for children who have lived together under group care in England and for whom a plan of group care is developed in this country, the standards provide for a combination of group care and the personal interest of an individual sponsor for each child.

\section{STANDARDS OF FAMILY-HOME CARE FOR CHILDREN \\ (For use of foster parents)}

\section{Issued August 1, 1940}

The general report of the 1940 White House Conference on Children in a Democracy recognized the importance of home and family as the first condition of life for the child. The contributions of the home to the growth, development, and education are summarized by the White House Conference as follows: ${ }^{1}$

The child has food and shelter if his family has a home and provides food.

He is content and happy if he is well, if he has parents and others to love and be loved by.

Education begins in the home, where he learns to speak, to walk, to handle things, to play, to demand, to give, to experiment.

\footnotetext{
${ }^{1}$ Children in a Democracy; general report adopted by the White House Conference on Children in a Democracy, January 19, 1940, p. 10. Children's Bureau, Washington, 1940.
} 
Religious faith is imparted in the family long before he goes to church.

Adventure and safety, contentment and rebellion, cooperation, sharing, self-reliance, and mutual aid are family experiences.

It is impossible to set down in words the qualities which assure to a child a successful foster-home experience. The following standards are intended as general guides and not as inflexible requirements.

\section{The comunnity in Which the family lives Should offer:}

A. Wholesome neighborhood influences.

$B$. Good health services and facilities for medical care.

C. Well-equipped schools.

D. Opportunities for church attendance and religious instruction.

E. Facilities for wholesome play and recreation.

$F$. Child-welfare and child-guidance service within the community or available to it.

II. The house in Which the Family Lives Should PRovide:

A. Protection from fire, accident, and disease, in conformity with local fire and sanitary ordinances; screening of windows; sanitary toilct and bathing facilities; safe water supply in accordance with local health-department standards; provision for storage and refrigeration of food; and clean and sanitary premises at all times.

$B$. Adequate light, ventilation, and heat.

$C$. Good sleeping quarters.

1. Separate sleeping rooms for children, used exclusively for bedrooms, with outside light and ventilation; preferably a separate bedroom for each child, but not more than two children in a room except in unusual situations.

2. A separate bed for each child, with good springs, a comfortable mattress, and sufficient, clean bedclothing.

D. Provision for outdoor and indoor play.

III. The family offering its home to the Child Should provide:

A. A complete family group, except in unusual situations. Both foster parents should be actively interested in caring for the child, and should be of an age suitable to meet the needs of the child whose care they are to undertake. All members of the family should be in good physical and mental health. One person in the family should have sufficient free time to give the necessary care, supervision, and companionship to the child.

B. Economic security based on a regular and reasonably secure income sufficient to provide for a comfortable living. 
$C$. Opportunities for the preservation of ties with parents. The foster parents should understand that this is a temporary plan for the child and that every avenue for the child to maintain his ties with his parents and his homeland ought to be utllized.

$D$. A normal place in the family. Consideration and affection for the child should be shown. He should be treated at all times as a member of the family with opportunity for full participation in family and community life.

IV. The care given the child should include:

A. Food, clothing, and accessories.

1. Wholesome, nutritious food properly prepared and sufficient in quantity. Formulas for infants should be prescribed by a physician.

2. Clean and attractive clothing, well-fitting and individually owned, kept in good condition, with sufficient changes for cleanliness, and suitable for all weather conditions.

3. Individual toilet articles, including towels, wash cloths, comb, and toothbrush.

B. Medical and dental care, including: Periodic health and dental examinations at least once a year and oftener in the case of children of preschool age; prompt correction of remediable defects, essential immunizations against communicable disease, and the services of a physician in the case of accident or illness, with nursing service and hospitalization when necessary.

C. Education.

1. Opportunity for attendance at a good school at least until the child reaches the age of 16 years. (Conformity with the requirements of the immigration regulations forbids any gainful employment of children under the age of 16 years, or after that age if admitted on a visitor's visa.)

2. Provision for attendance at church or Sunday school.

D. Home training.

1. Definite participation in home activities suitable to the age and physical development of the child.

2. Training in good health habits and personal hygiene.

3. Reasonable allowance for spending money.

4. Provision for toys and personal possessions.

E. Outside contacts.

1. Opportunities for suitable companionship, friendship, participation in community activities, and adequate and suitable recreation.

2. Assistance in maintaining communication with relatives and friends abroad. 
V. The contacts of the FaMily With the supervising Child-CaRe AGENCY SHOULD INCLUDE:

A. Prompt notification of the agency with regard to change of address, illness, or any matters which may be detrimental to the child's health, welfare, or happiness.

B. Reports to the agency concerning the child's progress in home and school.

$C$. Readiness to consult the agency when any developments take place that seem to present difficulties, and in any event whenever any marked change in the home situation occurs.

$D$. Opportunity for contacts by representatives of the agency with the child and foster parents.

\section{GROUP CARE OF CHILDREN}

\section{Memorandum issued September 20, 1940, as revised}

Children coming to the United States as guests for group care have the same basic needs for individualized consideration of their particular problems, and for a feeling of belonging and of sharing interests with other individuals, both adults and children, as those receiving care in foster homes. One of the commonly accepted forms of group care of children is the boarding school. Such a school provides group life interspersed with periods of vacation during which times the children return to the natural relationships and experiences found within a family. Other forms of group care provide for school attendance at community schools, thus facilitating acquaintance and friendship with children outside the group.

The following statement interpreting the needs of children receiving group care emphasizes the value of family relationship for these children and points out the necessity for basing all programs of group care on accepted standards of child care and services.

The emphasis placed by the Children's Bureau upon care in family homes is based upon the desirability of giving children coming here for safety an opportunity for home life and community contacts as nearly normal as possible. It is believed that their stay in the United States should provide both safeguards to assure the conservation of ties and interests centering in their homeland, and opportunity for care in accordance with individual needs, for formation of friendships, and for participation in the general life of the people of the United States, whose guests they are.

The objectives outlined above, it is believed, can be met under certain circumstances through a combination of group and familyhome care. In all such cases there should be an individual family 
responsible for the child in whose home he can spend vacations and to whose members he can look in emergencies. In other words, there must be an individual sponsor for each child. Preferably group care should be confined to cases in which the children have lived together as a group before coming to the United States.

All groups providing care for children should be organized and conducted in accordance with the Children's Bureau standards for child-care agencies and for medical care, insofar as they apply to group care. Specifically, the following points should be kept in mind:

1. The care provided should be under the immediate supervision of a child-care agency designated by the Children's Bureau for service to children, or when such an agency is not available, under such direct supervision as may be approved by the Children's Bureau.

2. The plan should be approved by and in compliance with the requirements of the State department of welfare and subject to the supervision of the department.

3. If the plan includes provision for full-time education, the educational facilities should be approved by the State department of education in conformity with policies set up by the United States Office of Education. All children of school age should attend full-time school at least until they reach the age of 16 years.

4. Provision should be made for wholesome recreation and leisure-time activities.

5. The plan should include adequate provision for medical care and health supervision.

6. The children should be housed in small units.

7. The services of a sufficient number of qualified social workers should be available, preferably through arrangements with a designated child-care agency. One social worker should not be expected to serve more than 50 children. One of the functions of the social worker should be to develop and maintain relationship with the families sponsoring the children and to arrange for their care in family homes when the plan seems desirable.

8. Records of all available information concerning each child and his family and of the child's progress while under care should be maintained.

9. The plan for housing, staff, and program of activities should be in conformity with accepted standards of group care and should be subject at all times to review and approval by the Children's Bureau. 


\section{Standards for Child-Care Agencies}

In designating - in consultation with State welfare departments-child-care agencies willing to take responsibility for the review of homes and the placement and supervision of children coming to the United States under the auspices of the United States Committee for the Care of European Children, the Children's Bureau has been guided by general standards for such agencies, issued June 28, 1940, and more detailed standards of foster care, issued August 2, 1940. These standards are to be regarded not as inflexible requirements but as general guides in the review of agencies and the development of foster-care programs.

Designated agencies are responsible, in the areas they serve, for visiting and reviewing family homes offering to care for European children, for selecting homes suited to the particular needs of the children assigned to the area by the United States Committee, for placing children in these homes, and for advising the foster parents and giving general supervision as to the ways in which the child's needs may be met most fully. They may also be responsible for reception care prior to placement. ${ }^{1}$

\section{GENERAL POLICIES GOVERNING THE DESIGNATION OF CHILD-GARE AGENCIES}

(For service to European children)

Issued June 28, 1940

I. Administration.

$A$. The agency should be approved by and should be under the supervision of the State department of welfare of the State in which it is located.

$B$. The agency should be fully qualified and equipped for childplacing service or it should be one which can be so equipped under

${ }^{1}$ For standards of reception eare, see pp. 14-18, and for standards of medical care, pp. 19-27.

$287875^{\circ}-41-3$ 
plans worked out with the United States Committee for the Care of European Children. The resources of the agency should include a well-organized and professionally staffed social-service department to select the foster homes and to provide the continuing supervision of care given to children in such homes.

$C$. The agency should maintain records of all available information concerning each child and his own family and complete reports of care given by the agency.

II. Service.

$A$. Temporary reception care, if provided, should be in conformity with the standards of the Children's Bureau of the United States Department of Labor.

$B$. All children received for care should be placed in family homes of their own religious faith, immediately or after a brief period of reception care, except when the child's special needs require other forms of care. ${ }^{2}$

$C$. Children received for care should be assured adequate medical care and health supervision, should attend school until at least the age of 16 years, and should not be gainfully employed prior to the age of 16 years, or after that age if admitted on a visitor's visa.

$D$. It is preferable that not more than two unrelated children should be placed in one home, and, in any event, there should be no more than four, except in the case of brothers and sisters.

$E$. The agency should retain responsibility for each child until he reaches the age of at least 18 years or has been returned to a parent or legal guardian, or transferred to other care with the approval of the United States Committee for the Care of European Children.

III. SUPERVISION.

$A$. The agency should agree that the Children's Bureau shall at all times have access to all premises and facilities used for the care of children and to all records of such children.

$B$. The agency should agree to make such periodic reports of the whereabouts, status, and care of the children as may be prescribed by the Children's Bureau.

2 See Group Care of Children, p. 5. 


\section{STANDARDS OF FOSTER GARE}

(For use of designated child-care agencies)

Issued August 2, 1940

I. Standards FOR the FOSTeR home.

A. Neighborhood and home.

1. The foster home should be located in a community offering wholesome neighborhood influences, facilities for health service and medical care, and accessibility to churches, desirable recreational facilities, and well-equipped schools.

2. A standard of living should be maintained by the foster family which makes possible normal family life in healthful and wholesome surroundings. There should be a homelike atmosphere.

3 . The foster home should conform to the sanitary ordinances of the city or town in which it is located. It should be kept clean and in a sanitary condition. Windows and doors should be screened.

4. There should be adequate fire protection consistent with State and local ordinances.

5. The home should have adequate light, heat, and ventilation, and should not be overcrowded.

6. Sleeping quarters should have ample light and ventilation. All sleeping rooms for children should be outside rooms. It is preferable that each child have a separate bedroom; if this is not possible, no more than two children should share a bedroom except in unusual situations. The child's bedroom should be exclusively for the use of the child or children occupying it and should not be used as living room, dining room, or for other purposes by other members of the family. Each child should have a separate bed, provided with good springs and a comfortable mattress. The bed clothing should be sufficient in quantity and should be kept clean and in good condition.

7. There should be adequate space for indoor play and a yard, or some place other than the street, for outdoor play. There should be provision in the home and in the neighborhood for recreational activities for older children.

8. There should be proper facilities for bathing. The maintenance of a high standard of hygiene and personal cleanliness should be expected in all foster homes.

9. The milk and water supply should conform to the standards set by the State and local health departments.

10. Adequate provision should be made for the storage and refrigeration of food. 
B. The foster family.

1. The foster family should be a complete family group, with both parents actively interested in caring for a foster child. The homes of widowed, divorced, or single women should be considered only on the basis of their special qualifications in relation to individual situations.

2. Foster parents should be well-balanced and mature individuals who can offer examples to a child of wholesome, adult relationships and who can exercise good judgment in the handling of a child. They should be in good health, both mental and physical. They should be capable of offering intellectual, spiritual, and moral guidance to the child.

3. The foster parents should be of an age suitable to meet the needs of the child whose care they are to undertake.

4. Family relationships of all individuals in the foster home should be wholesome and of such a nature that the addition of a foster child can be accomplished without undesirable results.

5. It is preferable that there be no adult boarders or roomers in the foster home.

6. There should be an income sufficient to provide a comfortable living for the foster family, and to make possible adequate recreation and a well-rounded family life. The income should be regular and reasonably secure. Unless fully adequate substitute care is provided, the foster mother should not be employed outside the home.

7. All members of the foster family should be in good health and free from communicable disease or any defect that would affect a child adversely. The agency should give consideration to the possibility of asking for physical examinations of members of the foster family.

\section{Standards of CARE AND SERvice.}

A. Care of the child in the foster home.

1. The child placed in the foster home should always be considered a member of the foster family and should be treated in all respects in the same manner as the foster parents' own children.

2. Foster parents should have a reasonable knowledge of the principles governing the feeding of children. The food supplied to the child should be of good quality, properly prepared and sufficient in quantity. Formulas for infants 
should be prescribed by a pediatrician, and the feeding of young children should be supervised by a physician.

3. The child should not be left in the home without adult supervision, particularly at night.

4. The child should be supplied with clean and attractive clothes that fit and are individually owned. The clothing should be kept in good condition, and there should be sufficient changes for cleanliness and protection against inclement weather. As a general rule, the child, if he is old enough, should have the privilege of selecting his own clothing under supervision of the foster mother.

5. The child should have his own individual place for his belongings, including clothing, toys, and other personal possessions.

6. The child should be provided with individual toilet articles, including towels, wash cloths, comb, and toothbrush. He should be taught good health habits and personal hygiene.

7. The child should be provided with necessary medical and dental care, which should include periodic health and dental examinations at least once a year and more than once a year in the case of a young child, prompt correction of remediable defects, essential immunizations, the services of a physician in case of illness or accident, and hospitalization when necessary.

8. Provision should be made for the child to attend school at least until the age of 16 , and for each child of suitable age to attend a church or Sunday school of his own religious faith.

9. Gainful employment of children under the age of 16 years is not permitted under immigration regulations governing admission of children to the United States. A child above that age admitted on a visitor's visa is not permitted to seek employment.

10. The child should have definite duties in the home which are suitable to his age and physical development, and he should be held responsible for their accomplishment.

11. Adequate and suitable recreation should be provided.

12. The child should participate in community activities. He should have an opportunity to make friends in natural ways. Normal neighborhood contacts and wholesome relationships between the sexes should be fostered. 
B. Selection of the foster home.

1. There should be a thorough review of the prospective foster home and a clear understanding between the foster parents and the agency before the child is placed. It is important that the foster parents know what is expected of them and that the agency know what the foster parents have to offer a child and also what these parents expect of the child and of the agency.

2. So far as is possible the foster home should be selected on the basis of its ability to meet the needs of a particular child of a similar cultural background.

3. The child should be placed in a foster home of the same religious faith as that of his parents. Adherence to this principle will prevent the development of problems which may arise when the attitudes of the foster family may be in conflict with the child's early experience.

4. The study of the foster home, its selection for a particular child, and the placement of the child in the home should be made by a responsible person who has an understanding of child-placing work.

\section{O. Placement of the child in the foster home.}

1. It is preferable that no more than two unrelated children be placed in one home and, in any event, there should be no more than four, except in the case of brothers and sisters.

2. Every effort should be made to place brothers and sisters in the same foster home or, if this is not possible, in the same community.

3. Before a child is placed in the foster home the foster parents should be given as much information as possible concerning the background of the child and any suggestions that might be helpful in the integration of the child into the family group.

4. If at all possible, the worker should talk the plans over with the child, describing the home and what is expected of him.

5. The adjustment will be made easier for both the child and the foster family if arrangements can be made for them to become acquainted before the child goes to the home to live. Consideration should be given to the possibility of the child's visiting in the foster home prior to placement, and, on the basis of this visit, participating in the decision as to whether he is to live in the home. 
D. Supervision of the child in the foster home.

1. There should be adequate supervision of the child in the foster home after placement. The foster parents and the social worker should counsel together regarding the child's care. The worker, through her experience in child placing, will be able to interpret to the foster parents a probable basis for the child's reactions, and the foster parents, through their observation of the child's physical and emotional development, may contribute to the worker's understanding of the child. Both the foster parents and the child should feel that the worker is a person who will help them work out their problems.

2. Both the worker and the foster parents should be aware of the differences in background of European and American children, and any problems arising should be considered and dealt with in the light of these differences.

3. The worker should thoroughly understand any situation that arises before she gives advice, and she should avoid blaming either the foster parents or the child if problems develop. Trouble may be due to the fact that the particular child cannot adjust in the particular home because of the background and previous experience of both, rather than to any fault of either the child or the foster parents.

4. The agency should be ready at all times to make such changes in plans as will be for the interests of the child, and it should be constantly alert to the developing needs of the child.

E. Records.

1. The agency should keep case records that include all necessary current information for each child placed in a foster home and for each foster home.

2 . The confidential nature of the records should be respected by everyone having access to them. 


\section{Care in Reception Centers}

European children entering the United States usually need a period of group care in reception centers for a sufficient length of time to allow plans to be made for their placement in family homes or in group care, and to determine their general physical condition and any special needs which may be significant with reference to plans for their placement. For children who have been exposed to communicable disease temporary care is especially important, both for their own protection and in order to prevent spread of disease. A brief period of reception care is usually necessary immediately after debarkation from boat or train, and a longer period of temporary care, frequently in the community to which the child is assigned, may be necessary prior to placement in a family home.

General standards of care of children in reception centers, prescribed by the Children's Bureau, relate specifically to reception centers used for temporary care, either at the port of debarkation or in the community to which the child is assigned for placement. In many respects, however, they are applicable to any form of group care.

\section{GENERAL STANDARDS OF CARE OF CHILDREN IN RECEPTION CENTERS}

Issued August 14, 1940

\section{General equipment of the center.}

The building or buildings selected for care of children for a temporary period should be chosen with major consideration for safety, sanitation, health, and comfort. Adequate space for both indoor and outdoor recreation should be provided. Preference should be given to the use of buildings in which children can be cared for in units accommodating not more than 50 children. (Single rooms are preferable to dormitories for most children of school age.) This 
policy would avoid the quarantining of large numbers of children and would make space available for the admission of new children in the event that communicable disease should develop in one unit.

Local or State autborities should be consulted with regard to rules and regulations relating to housing, fire hazards, sanitary equipment, water supply, examination of food handlers, and other sanitary requirements.

\section{A. Safety.}

Provision for safety should include removal of all possible fire hazards, such as accumulation of rubbish and defective electrical wiring, and should include a sufficient number of safety exits, as required by local fire prevention regulations. Precautions should be taken to prevent accidents by providing night lights in halls and toilets and over exits, screens or bars on windows, hand rails on stairways, and gates across stairs where needed for the protection of small children.

\section{B. Sanitary and health provisions.}

1. Pure water with adequate facilities for drinking and bathing.

2. Sufficient toilet and bathing facilities for the number and sex of children under care. Provision should be made for individual towels, washcloths, tooth brushes, and combs, with clear marks of identification.

3. Well-ventilated and sunny premises, particular attention being given to sufficient window space in sleeping quarters.

4. Sanitary care of food as to refrigeration and storage, preparation, and serving.

5. Proper laundering of linen and wearing apparel to reduce the danger of spread of infection.

6. Facilities for keeping the entire building clean and sanitary, including the care of dishes, toilets, and baths according to standards of the local health department.

\section{Sleeping quarters.}

1. Single rooms for children of school age, or separate dormitories for boys and girls over 5 years of age. All rooms and dormitories should have individual beds, well spaced, with clean, adequate bedding. Arrangements should be made for space for each child's clothing and other personal effects. 
2. Night care, which should include supervision of all children, lights in the rooms of young children, and easy access to toilet facilities.

D. Space for special health and welfare services.

1. Separate rooms should be available for isolation and care of sick children or those suspected of having a communicable disease until appropriate arrangements can be made for other care. There should be a minimum of 4 beds available for isolation of sick children for every 100 children under care.

2. Special facilities should be available for newly arrived children until through a medical examination assurance is given that they can without danger join in activities with resident children.

3. Space should be provided for examining rooms for physicians and for special conferences with individual children.

\section{Program of the Reception center.}

\section{A. Study of the children.}

The time spent by children in a reception center provides an opportunity to obtain some understanding of each child's physical and mental condition, and his need for medical, dental, or other care. It also provides an opportunity to discover each child's previous school experience and educational needs, and to understand his social background and special interests, and any personality problems that must be taken into consideration in his final placement. It is important that each reception center have on its staff well-equipped persons who, with the assistance of special consultants, can undertake a basic study of each child and his needs.

\section{B. Health protection.}

1. There should be at least one nurse for every 50 well children.

2. Medical supervision should be continuous during the time that children remain in residence and arrangements should be made for hospital care or other special medical services needed by children.

3. Special precautions should be taken to minimize the danger of introduction of communicable disesases when new children are admitted. 
4. Special attention should be paid to the nutritional needs and food habits of children. It is desirable to have the services of a nutritionist or dietician or opportunity for consultation with one.

\section{Other aspects of the program.}

1. Guarding of identification is important, through careful preservation of tags, personal effects, and records.

2. Children should be encouraged to maintain contact with their families, relatives, and friends through correspondence.

3 . The religious affiliation of the child or the child's family should be respected in arrangements for meeting the religious needs of the children through utilizing the resources of the religious groups in the community.

4. Recreation programs requiring physical activity are particularly important, since they relieve emotional strain, develop new friendships, and help children to become acquainted with various forms of play and recreation which may be especially characteristic of their new environment. Inexpensive equipment, such as toys, bats and balls, dolls, radio, and books which help to illustrate child life and the interests of children in this country should be provided. Excursions to local points of interest should be arranged when possible. Qualified group leaders should be available for these programs.

5. The mental health of the child should be safeguarded by recognition of his personality needs and by plans to meet them through careful handling of his individual problems by staff members, or by utilization of the child-guidance resources of the community.

6 . The special needs of children, particularly educational or medical needs, should be met by the most advantageous possible utilization of local resources.

\section{The STAFF.}

\section{A. The superintendent or director.}

The effectiveness of any program of group care of children is vitally affected by the type of person appointed to direct, coordinate, and develop its services. The position of superintendent or director requires a person with skill in institutional management, understanding of child care and the factors affecting the development of children, and ability to deal effectively with professional and nonprofessional members of the staff. 
B. Professional staff.

The standards of education, training, and experience required of persons employed to provide professional services should meet the accepted standards established by recognized professional organizations in the fields of pediatrics, psychiatry, nursing, dietetics, and social work.

C. Persons in direct charge of the children.

Supervisors of units within the center should have the ability to direct the care of children in groups, yet not lose sight of the individual. 


\section{Medical Care of Children}

Arrangements for the care of any child should include plans to meet his health needs. Standards for medical care of children have been drawn up to assist in planning the whole program of care to be given and services to be provided at reception centers, and to serve as guides in organizing the health program and medical services of the agencies assuming responsibility for placement and supervision of the children in foster homes. These standards outline a program for the medical care each child should receive, the organization of medical services necessary to provide such care, and the qualifications needed for personnel giving health service.

\section{STANDARDS FOR MEDICAL CARE ${ }^{1}$ \\ Issued August 28, 1940}

It is understood that the European children who are sent to the United States for care will have been examined by physicians previous to embarkation, and that only those considered physically and mentally sound will be sent to this country. The information available in the United States regarding the past medical history or present health of these children, however, may be very limited. In order to facilitate proper placement, therefore, information must be obtained regarding their physical, mental, and emotional status. This information should be as complete as is possible without adding unduly to the strain and tension which in some degree is unavoidable under the circumstances.

\section{Program for Medical Care}

The program for medical care is designed as a guide for determining the special health needs of the children and providing for those needs in such a way as to protect their own health and the health of other children with whom they may come in contact. Many of the recommendations for medical care have been adapted, with the permission of the Child Welfare League of America, from its booklet, "A Health Program for Children in Foster Care." 2

\footnotetext{
${ }^{1}$ Prepared by the Children's Bureau in consultation with an advisory group (see p. viI).

2 See footnote 5 , p. virI.
} 
A program for medical care of guest children should include plans for appropriate care of any children who become ill previous to placement, plans for medical examination of all children, and plans for continued medical supervision of the children after placement.

\section{Provision for medical CARe of Sick children.}

At all places where guest children are to be cared for, suitable arrangements should be made in advance for adequate medical care for any children who become ill. This will involve provision for a physician to be on call at all times and for nursing care and hospital facilities to be available when needed. If large numbers of children are cared for at one time in a reception center, responsibility for medical supervision of specific groups of not more than 50 to 100 children should be assigned to individual physicians. These physicians should call daily at the center, while the children are in residence, to examine any children whom they or others of the staff believe to be in need of special attention. Arrangements made in advance for hospitalization of sick children, especially those with communicable disease, and for the consultant services of specialists if needed, will avoid confusion and make the necessary care more promptly available if emergencies arise.

\section{Examinations before placement.}

\section{A. Arrangements for examination in reception centers.}

Centers in which appropriate facilities can be made available should be used for the care of children during a period of observation preliminary to placement. Children known to have been exposed to communicable disease should remain in these centers until after the incubation period for the disease has expired.

The period of observation before the child is placed in a foster home should be utilized to gain information regarding the child's health status. A complete medical examination should be made as soon as possible after the child arrives at the center where he is to remain for observation. This will give opportunity for any follow-up examinations found necessary without, in most cases, prolonging the stay in the center, and will make the information acquired available promptly to those arranging placement.

The findings on examination should be recorded in triplicate on a form provided for this purpose. Recommendations for special examinations or treatment should be recorded and should indicate whether the examination or treatment should be arranged before or after the child is placed. After all examinations that are to be made before placement have been completed, the findings should be summarized briefly on the record, and any 
recommendations with regard to placement of the child or medical care after placement should be noted. One copy of this record should be retained at the center where the examination is made, one copy should go with the child to the placement agency, and one should be sent to the United States Committee.

For children who present special health or emotional problems, plans for placement should be made only after consultation between the physician, the child-welfare workers, and the psychiatrist (child-guidance worker).

\section{$B$. The content of the medical examination.}

1. Physical examination by pediatrician.

Note should be made of the following:

Height.

Weight.

Temperature.

Skin.

Scalp.

Eyes-Pupillary reaction.

Vision.

Eye grounds.

Other.

Ears-Otoscopic.

Hearing.

Other.

Nose.

Teeth-Condition.

Occlusion.

Other.

Gums.

Throat-Pharynx.

Tonsils.
Adenoids.

Glands.

Thyroid.

Chest.

Heart.

Lungs.

Abdomen.

Secondary sex characteristics.

Genitals.

Reflexes.

Extremities.

Feet.

Posture and spine.

Nutrition.

Signs of endocrine imbalance.

Signs of emotional instability.

Intellectual equipment (apparent).

Presence of smallpox-vaccination scar.

Special attention should be given to the child's nutritional status as determined by clinical evidence. Evidences of undue emotional disturbance should be noted.

2. Laboratory examinations.

Urinalysis: tests for albumen and sugar; microscopic examination. Blood examination: hemoglobin determination, examination of smear (cell counts desirable but not essential).

Cultures, when indicated, of throat, and of any vaginal discharge that might be infectious.

3. Tests.

Syphilis test.

Tuberculin test: Mantoux or Patch test (on left arm). Should be read on third to seventh day. 
Schick tests (on right arm). Should be read on fourth to seventh day.

4. Follow-up examinations, immunizations, and treatment when indicated for individual children.

The above examinations will reveal certain children for whom additional examinations are indicated or who should receive certain immunizations or treatment for some specific condition. These additional procedures include:

$a$. Diphtheria immunization for children with positive Schick test. First dose $(0.5 \mathrm{cc}$.) of toxoid should be given as soon as possible after Schick test is read, and two additional doses $(1.0 \mathrm{ec}$. each) should be given at intervals of 3 to 4 weeks. Recommendation for administration of remaining doses should accompany a child who is transferred elsewhere before completion of immunization.

$b$. Smallpox vaccination for children who do not have a vaccination scar.

c. X-ray of chest and abdomen for children who have positive tuberculin test.

Other conditions may require other special examinations, such as ophthalmologic examination, stool examination, basal-metabolism test, or fluoroscopic examination, and for some conditions treatment may be necessary before the child is placed.

5. Dental examination and tests of vision and hearing. These may be given either before or after placement (see sec. III-A).

\section{Medical supervision after placement.}

Certain tests may be given either before or after placement since in most cases they can safely be postponed until after the child is placed. They should be given before placement in cases of gross defects which are noticed at the time of the general physical examination. If there is question as to whether they can be arranged after placement, the dental examination and tests of vision and hearing should be planned as part of the examination before the child is placed.

A. Special examinations and immunization.

1. Dental examination by a dentist. This may be given as part of the admission examination of the child or may be given after placement, but it is important that complete information regarding the condition of the teeth should be 
a vailable to the placement agency at an early date in order that arrangements for necessary dental care may be included in plans made for the child.

2. Tests of vision, with dilatation of the pupils, by an ophthalmologist, should be given before the child enters school.

3. Tests of hearing, with an audiometer if possible, should be given before or shortly after admission to school. It may be possible to arrange for the test to be given through the schools.

4. For children placed in certain areas, physicians may recommend typhoid immunization.

5. Psychiatric and psychological study are desirable for children presenting difficulties of social or educational adjustment and development. Such study may be indicated before placement, but ordinarily it would be of greater value after the child has had some experience in the foster home.

\section{B. Health examinations.}

Children under 6 years of age should be given a health examination at least every 6 months; older children should have such an examination at least once a year, preferably at the beginning of the school year. For some children physicians may recommend more frequent examinations.

The health examination should include a physical examination, laboratory examinations, and follow-up examinations as outlined under section II-B: 1,2 , and 4 .

\section{Other health services.}

1. Dental examinations.

Each child should have an examination by a dentist every 6 months, with prophylaxis and with treatment if indicated.

2. Correction of remediable defects and treatment of other abnormal conditions.

Any conditions found at the examination before placement, or at later examinations, which may interfere with the child's health or well-being, should receive appropriate treatment.

3. Medical care during illness.

For every child in a foster home the services of a physician should be available in case of illness. Hospital facilities and the consultation services of specialists should be available when needed. 


\section{Organization for Medical Care}

\section{Organization of Medical services for Centers Providing} TEMPORARY CARE OF CHILDREN.

\section{A. Direction and organization of medical services.}

In any city in which children are to be cared for temporarily before assignment to designated agencies or individuals, a medical director should be appointed who will be responsible for the organization and administration of all medical services for the children while they are under temporary care.

In the preliminary organization of the medical services, consultation with representatives of the State and local health departments will facilitate coordination of effort in obtaining maximum protection for the health of the guest children and of others with whom they will come in contact.

B. Personnel for medical services.

1. The staff needed.

In addition to the medical director other physicians should be appointed if needed to provide adequate medical supervision of the children in the centers. One physician should be responsible for not more than 50 to 100 children. The services of a dentist should be available for emergency dental care. Nurses, who will preferably reside in the center, should be appointed in the proportion of approximately 1 nurse for every 50 well children.

For medical examinations before placement the personnel required will include physicians, nurses, laboratory technicians, and voluntary assistants. Dentists, ophthalmologists, and experts in audiometer testing will be needed if the dental examination, vision testing, and examination of hearing are to be given previous to placement. The number of physicians and the total hours of physicians' services planned for admission examinations should be sufficient to allow a minimum of 15 minutes for the examination of each child, and to allow for necessary follow-up examinations, the reading of Schick and tuberculin tests, giving immunizations, and so forth.

The services of specialists should be available for consultation if needed for diagnosis or treatment. ${ }^{1}$

\footnotetext{
1 The American Academy of Pediatrics, 636 Church Street, Evanston, Ill., and other organized professional groups have expressed their readiness to assist in the development of programs for medical care of these children. Through consultation with the local representatives of such organizations it may be possible for agencies to obtain assistance in the development of their medical programs and the services of qualified personnel.
} 
2. Qualifications of personnel for health services.

a. Pediatricians.

Physicians selected to organize and direct medical services and to give medical examinations, health supervision, and general medical care should be skilled in the care of children. Whenever possible pediatricians should be selected.

$b$. Other specialists.

Physicians called in consultation or those giving special examinations, such as ophthalmological examinations, should be recognized specialists in their fields, with experience in the care of children. It is particularly important that psychiatrists and psychologists should have had training and experience in child guidance and in the treatment of children's problems.

c. Dentists.

Dentists should have experience in dental work for children.

d. Nurses.

Nurses should have had experience in the care of children. Training and experience in public-health nursing, in children's clinics, and in care of well children, as for example, in connection with camp programs, are especially valuable. If several nurses are to be employed in one center, a nurse who has had supervisory experience as well as experience in the care of children should be appointed supervisor.

\section{Preliminary arrangements.}

Every effort should be made to create an environment providing an atmosphere of repose and giving the child a sense of security, to keep him occupied with tasks or recreations which interest him and to surround him with the affection which he needs. Examination procedures should be kept as informal as possible in order to avoid frightening children who are already under the strain of adjustment to a new environment.

The assignment of individual responsibilities and duties as definitely as possible will avoid confusion and duplication of effort.

Preliminary arrangements should be made for hospitalization, if needed, for sick children.

For centers at which admission examinations are to be given, arrangements should also be made for medical supplies, including 
materials for special tests, and for facilities for laboratory tests, $\mathrm{X}$-ray examinations, and so forth.

\section{Organization of MEdicAl SERVICES For CHILDREN IN FOSTER HoMES.}

Each agency accepting European children for placement in foster homes should have a well-organized program for medical care of children under its supervision. The direct responsibility for medical care may be retained by the agency or may be placed with foster parents. In either case there should be a clear understanding between the agency and the foster parents regarding the policies with respect to medical care.

The medical program should be administered by or in consultation with a physician. It is desirable that agencies and foster homes should have access to consultant services by specialists for children presenting unusual problems. Consultation service to the staff of the agency by a psychiatrist or psychologist regarding children presenting special problems of adjustment will be particularly helpful. Qualifications of personnel responsible for the health program should be the same as those outlined for personnel for health services in reception centers.

A. Medical services provided by the agency directly or in cooperation with community agencies.

The medical services should be under the direction of a physician and should include the services of a qualified nurse. They should include provision for periodic medical and dental examinations, special examinations when indicated, interpretation of findings to foster parents, and necessary correction of defects. Physicians should be on call to visit sick children in the home, and hospital facilities should be available when needed.

It is important that foster parents should know how to obtain medical services or authorization for surgical operations during hours when the agency offices are closed.

The agency should keep a complete health record for each child, including the findings at medical or dental examinations, medical or dental care given, defects corrected, note of illnesses or operations, and so forth.

B. Medical services provided by foster parents.

When the direct responsibility for medical care is placed with the foster parents, the agency should be responsible for general supervision of the health program. In order to do this the agency either should have a physician on its staff or should have the consultation services of a physician. The agency should require that the choice of physician and dentist by the 
foster parents be subject to its approval, and should keep in sufficiently close touch with the foster parents to ascertain whether the recommended health program is being carried out. Public-health-nursing service through the agency or a cooperating community agency should be available to all children requiring such service.

It may be advisable under some circumstances for the agency to retain responsibility for certain aspects of the medical care which might be difficult for the foster parents to obtain, such as audiometer testing or psychological study.

The foster parents should have a clear understanding of what constitutes a good health program for children and should be prepared to carry out such a program. They should also understand how to obtain authorization for surgical operations if necessary.

Reports of examinations and treatment should be obtained by the agency from the child's physician and dentist, either directly or through the foster parents, and complete health records should be kept by the agency. 


\section{Appendix._Forms Used in the Designation of Agencies}

\section{NOTICE OF PROVISIONAL DESIGNATION OF CHILD-CARING AGENCY}

By direction of Katharine F. Lenroot, Chief of the Children's Bureau, United States Department of Labor, you are hereby notified that the

has been provisionally designated as an agency adequately equipped to cooperate with the United States Committee for the Care of European Children in the investigation of foster homes and in the care and supervision of children who are subsequently placed in these homes.

C. B. Form No. 1

Reply to: 215 Fourth A venue, New York, N. Y.

\section{U. S. DEPARTMENT OF LABOR CHILDREN'S BUREAU WASHINGTON}

\section{DESIGNATION OF CHILD-CARE AGENCY FOR COOPERATION WITH THE UNITED STATES COMMITTEE FOR THE CARE OF EUROPEAN CHILDREN}

You are hereby notified that your agency

has been designated as an agency adequately equipped to cooperate with the United States Committee for the Care of European Children in the review of foster homes and in the care and supervision of children who are subsequently placed in these homes.

Katharine F. Lenroot, Chief. 


